\title{
Regulações do corpo e da parentalidade durante o pré-natal em mulheres jovens de camadas populares
}

\author{
Regulation of the body and parentality during the \\ prenatal period in working-class young women
}

Alfonsina Faya Robles*

\begin{abstract}
Resumo: A partir de duas pesquisas etnográficas realizadas com mulheres jovens de camadas populares usuárias dos serviços de saúde pública, no Recife e no Rio de Janeiro, no artigo analisamos as relações destas com os profissionais e serviços de saúde de proximidade na construção de experiências da gravidez. Destacamos a maneira como os atendimentos do pré-natal têm se convertido em um dispositivo de regulação não somente de comportamentos e práticas corporais ligadas ao "cuidado de si" e do "outro a vir", mas também das relações de parentalidade. Seguindo esse escopo, observamos quatro técnicas de regulação sanitária: a assignação à maternidade, a construção de um "projeto de criança", a formação de "grupos de discussão" e a mobilização da categoria de "risco". Em conclusão, relativizamos a força disciplinar do dispositivo para compreender como as experiências da gravidez são construídas pelas mulheres, bem como para enfatizar as mudanças nos regimes de regulação na área da saúde materno-infantil.

Palavras-chave: Pré-natal. Camadas populares. Regulação. Corpo. Parentalidade.
\end{abstract}

\begin{abstract}
Based on two ethnografic research projects with young working-class women assisted by public health services in Recife and Rio de Janeiro, this article we analyse the relationships between these women and health professionals during pregnancy. We focus on how prenatal consultations became a regulation apparatus not only for body behaviours and practices linked to "self care" and "the one to come" but also for parental relationships. As a result of this focus, we can observe four sanitary regulation techniques: assignation to motherhood, construction of a "child project", discussion groups and the use of the category "risk". In conclusion, we put in perspective the disciplinary force of the apparatus in order to understand how the experiences of pregnancy are built by the women themselves and to illustrate the changes occurring in the regulation methods.
\end{abstract}

Keywords: Prenatal. Working-class. Regulation. Body. Parentality.

\footnotetext{
* Doutora em Sociologia pela Université de Toulouse II - Le Mirail (Toulouse, França), é pesquisadora associada ao Laboratoire Interdisciplinaire Solidarités, Sociétés, Territoires (Lisst) da mesma universidade e pós-doutoranda no Instituto de Medicina Social da Universidade do Estado do Rio de Janeiro, RJ, Brasil, com bolsa PDJ CNPq <afaya@univ-tlse2.fr>.
} 


\section{Introdução}

As questões trazidas no presente artigo surgem da pesquisa desenvolvida para a tese de doutorado em Sociologia, que trata da experiência da maternidade em camadas populares do Recife, assim como da pesquisa de pós-doutorado, em andamento, sobre gravidez na adolescência no contexto de uma favela "pacificada" do Complexo do Alemão, no Rio de Janeiro. ${ }^{1}$ O propósito de ambas pesquisas, apesar de retratarem contextos sociais e sanitários diferentes, é o de compreender a construção de experiências maternas em mulheres de camadas populares. Mais especificamente, buscou-se entender as relações que as mulheres mantêm com os profissionais e serviços de saúde de proximidade, a partir de três momentos chaves nesse processo: a gravidez, o parto e o pósparto. Contudo, neste texto serão apresentados e analisados somente alguns dos resultados concernentes ao momento da gravidez e do pré-natal, privilegiando-se os pontos de convergência dos contextos empíricos.

Foram observadas diferenças substanciais nessas construções a depender da idade da mulher. Não somente nas vivências familiares e trajetórias pessoais, mas também nos tipos de atendimento e normatividades dos quais as mulheres são alvo, conforme a idade. Destarte, geralmente as mulheres jovens e "adolescentes" aparecem como um grupo tido como "vulnerável", "problemático" ou de "risco" e necessitando de intervenções específicas por parte dos profissionais de saúde e politicas públicas. É por esse grupo específico que se interessa este texto.

O desenvolvimento e a expansão das políticas de atenção na saúde materno-infantil no Brasil têm sido um ganho para as mulheres do país. Desde os anos 1990, como Víctora et al. (2011) sugerem, as mudanças demográficas e epidemiológicas que afetaram a saúde materno-infantil no Brasil (baixa taxa da natalidade, aumento do uso de contraceptivos "modernos", redução da mortalidade infantil etc.) estão intimamente relacionadas com a expansão do sistema público de saúde, o desenvolvimento de programas verticais e de estratégias orientadas para populações com indicadores baixos, como é o caso das regiões mais pobres do país, como o Nordeste. Um elemento fundamental deste desenvolvimento foi a criação, promoção e sistematização do atendimento médico durante o pré-natal a partir de ações programáticas, protocolos e políticas em vários níveis administrativos e territoriais. Assim, $60 \%$ das mulheres que deram à luz em 2010 no Brasil tinham feito sete ou

\footnotetext{
${ }^{1}$ A tese de doutorado foi defendida em 2011 na Université de Toulouse (França) sob a direção da professora Angelina Peralva. A pesquisa de pós-doutorado é realizada no Instituto de Medicina Social da Uerj sob a direção da professora Maria Luiza Heilborn e conta com o apoio do CNPq.
} 
mais consultas pré-natais, como recomendado pela Organização Mundial da Saúde.

Na Região Nordeste, embora esta proporção seja menor (45\%), ela aumentou consideravelmente nos últimos dez anos (em 2000, a proporção de mulheres com sete ou mais consultas era de apenas 32\%) (Brasil, 2000; 2010). De fato, observa-se na região Nordeste a maior queda no número de casos de gravidez sem assistência pré-natal entre 2002 e 2007 (-33,7\%). Na cidade do Rio de Janeiro, a variação do número de consultas do pré-natal igual ou maior de 7, foi de 55,3 para $67,5 \%$ entre os anos de 2000 e 2006. A expansão da atenção pré-natal foi, no entanto, diferenciada na cidade. A ampliação do SUS e da Estratégia Saúde da Família (ESF) não se deu no Brasil de maneira homogênea e sistemática. Caetano e Dain (2001) chamam a atenção para a disparidade na implantação dessas estratégias em municípios de grande porte, sobretudo, nas capitais. A Área Programática 3.2, que recobre uma parte do Complexo do Alemão (Engenho da Rainha e Inhaúma), apresentou de 2000 a 2006 níveis de cobertura pré-natal levemente abaixo da média, e variações também próximas ao incremento observado para o município. A Área Programática 3.1 (a qual recobre a maior parte das comunidades do Complexo), entretanto, teve as maiores variações ou ampliações de cobertura pré-natal - com aproximadamente $30 \%$ de aumento. Esta área parte de percentuais em torno de $50 \%$ em 2000, para algo em torno de $65 \%$ em $2006 .{ }^{2}$

Assim, ficar grávida no Recife ou no Rio de Janeiro supõe cada vez mais, para as mulheres de camadas populares, a imersão na esfera médica. Se as estatísticas atestam um acréscimo em termos de aceso, poucos trabalhos porém têm se dedicado à análise das mudanças nas formas de regulação que a expansão de um dispositivo sanitário produz nos corpos grávidos das mulheres, sobretudo, das jovens, assim como as formas de subjetivação que essas mudanças têm produzido.

Frente às especificidades contextuais que apresentam as cidades do Rio de Janeiro e de Recife, a escolha para este texto foi a de apresentar os pontos de convergência observados entre os dois contextos empíricos. A análise centrase então nas relações entre os serviços e as mulheres e deixa as diferenças

\footnotetext{
${ }^{2}$ A chamada Área Programática 3.1, que abrange parte do Complexo do Alemão, é administrada pelo Viva Comunidade - Projeto da ONG Viva Rio, que foi contratada em janeiro 2010 e implantou 41 equipes de Saúde da Família na região. Em agosto do mesmo ano, esse número havia dobrado. Em outubro de 2011, o Viva Comunidade já administrava 122 equipes de saúde, segundo informações obtidas em sua página na rede. Já a área programática 3.2, que também inclui regiões que compõem o Complexo do Alemão (Engenho da Rainha e Inhaúma), é gerenciada pela Associação Paulista para o Desenvolvimento da Medicina (SPDM) desde o ano de 2009.
} 
socioculturais mais específicas na construção de sentido das experiências para um trabalho posterior, o qual se impõe fortemente. Nesses pontos de convergência observam-se mudanças nas modalidades da regulação da saúde reprodutiva que se operam nos serviços que atendem mulheres de camadas pobres.

Tais regulações aparecem não somente como modeladoras dos corpos grávidos na procura de resultados sanitários (baixa da mortalidade infantil e materna, assiduidade ao pré-natal etc.), mas também como ajustes da relação social de maternidade que as mulheres jovens devem construir com os seres a vir. Destacamos então a maneira como as consultas do pré-natal têm se convertido não somente em um dispositivo de regulação de comportamentos e práticas corporais ligadas ao "cuidado de si" (Foucault, 1984) e do "futuro outro" corpo, mas igualmente como locus de regulação das relações de parentalidade (Grossi, 2003; Uziel, 2006), ${ }^{3}$ pela transmissão de normas específicas para o cumprimento do papel materno nas mulheres jovens. Assim, as regulações e normatividades agindo no corpo gravídico vêm atreladas àquelas que procuram a captação rápida da mulher grávida para a construção de um "projeto de criança" nas mulheres jovens, as quais geralmente têm gravidezes não-previstas (Bajos e Ferrand, 2002). A formação de grupos prioritários de atenção e a visão da gravidez a partir da categoria sanitária de "risco" estão ligadas a novas técnicas de transmissão de normas, onde a "palavra", o "acompanhamento" e a "escuta" tomam um lugar central.

A primeira fonte de dados para nossa reflexão é a pesquisa de doutorado, que se baseia num trabalho etnográfico realizado em 14 meses, em 2005-2006 e 2008 em três maternidades públicas, com diferentes níveis de complexidade (duas tinham serviço de pré-natal de alto risco) e em um bairro da periferia de Recife e sua Unidade de Saúde da Família. Nessa área, foram acompanhadas as práticas dos profissionais e a experiência de 12 (doze) mulheres, ao longo de vários encontros em seus domicílios, na unidade ou em espaços de sociabilidade do território. A segunda fonte de dados provém da pesquisa de pós-doutorado em andamento "Experiência da gravidez e juventude: trajetórias e itinerários em uma favela pacificada", se insere numa problemática relativa às políticas de

\footnotetext{
${ }^{3}$ A noção de "parentalidade" é um neologismo que traduz os termos anglo-saxões de parenthood e de parenting, os quais designam respectivamente a condição de pai e mãe e as práticas ligadas aos papéis parentais, o conjunto cultural e socialmente construído de funções dos pais para com a prole. Ela engloba a maternidade e a paternidade, permitindo uma dessexualização dos atributos associados a cada "parente", assim como também uma desmultiplicação e fragmentação desses papéis entre diversas pessoas (multiparentalidade, monoparenatlaidade, homoparentalidade etc.). Para um aprofundamento da questão da parentalidade nas ciências sociais no Brasil, ver os trabalhos de Miriam Grossi e Anna Paula Uziel, entre outros.
} 
saúde pública como vetores (re)produtores de normas de gênero e à regulação das práticas reprodutivas das camadas populares. Baseada numa perspectiva etnográfica, a pesquisa faz também a análise das implicações da intervenção do estado brasileiro na gestão da vida em um contexto particular de recuperação de territórios ocupados pelo tráfico, como é o caso do Complexo do Alemão.

Ao longo do texto, veremos como a expansão do atendimento do pré-natal opera mudanças nas experiências maternas das mulheres de camadas populares, assim como as especificidades das novas formas de regulação dos comportamentos de mulheres jovens. O contraste entre as duas pesquisas permite revelar, para além das especificidades locais, a construção de tecnologias individualizantes das experiências reprodutivas das mulheres de Recife e do Rio de Janeiro, mas também certa performatividade (Butler, 2004) nas experiências das mulheres, as quais desenvolvem táticas de distanciação dos modelos veiculados pelo dispositivo do pré-natal.

Com tal objetivo, abordaremos o processo de construção da "gravidez precoce" como problema de saúde pública, tal como ele se desenha hoje, alcançando novos estágios de "institucionalização" (Heilborn, 2006). A expansão do sistema de saúde pública vem atrelada a esta construção assim como a formação de um dispositivo que tenta regular esse "problema de saúde". Em seguida, aprofundaremos a análise das diversas significações e lógicas envolvidas nas relações estabelecidas entre as mulheres jovens e os serviços de saúde na construção da experiência gestacional, desenvolvendo as ideias expostas anteriormente, a partir de quatro técnicas de regulação observadas no trabalho de campo: a "assignação materna", o "projeto de criança", o grupo prioritário e a categoria sanitária de risco.

\section{A "gravidez na adolescência" como "problema de saúde pública" e expansão do pré-natal: elementos para a discussão}

Para alcançar o cerne da discussão - as mudanças introduzidas nas experiências de mulheres jovens grávidas de camadas populares a partir de regulações sanitárias -, duas contextualizações fazem-se necessárias. A primeira faz referência à construção da gravidez na adolescência como problema de saúde pública, enquanto a segunda, ao desenvolvimento do próprio sistema de saúde e às mudanças nas suas modalidades de regulação.

Há alguns anos, as taxas de fecundidade na adolescência vêm perdendo peso nas taxas totais de fecundidade no Brasil, porém, a maternidade na adolescência continua sendo um fenômeno social de grande envergadura. Assim, a taxa específica de fecundidade das jovens de 15 a 19 anos apresentou um movimento ascendente nos últimos censos, apesar da taxa de fecundidade total 
ter declinado neste período. A participação relativa cada vez mais importante na fecundidade total, chamada de rejuvenescimento da fecundidade, vem sendo destacada por alguns autores (Berquó e Cavenaghi, 2005; Simões, 2006; Corrêa, 2004), retratando um modelo cada vez mais jovem da fecundidade brasileira. Como lembra Heilborn (2006, p. 30): "A gravidez precoce sobressai particularmente no contexto de redução da fecundidade [...]".

Na cidade do Rio de Janeiro, a proporção de nascidos vivos de mães adolescentes em 2011 era de 16,32\%, enquanto no Recife essa proporção elevava-se a $17,04 \%$. Enquanto o estado do Rio de Janeiro tem as taxas mais baixas de fecundidade do país (1,6 filhos por mulher) e os dados do último censo (IBGE, 2010) mostram um gradual retardo na idade de reprodução em comparação com os anos 1990, sabemos, entretanto, que no Complexo do Alemão um quarto dos nascimentos em 2010 foi de mulheres de menos de 19 anos. Os dados da Secretaria Municipal de Saúde mostram que, para um total de 282 nascidos vivos no Complexo do Alemão em 2010, 23\% foram de mães adolescentes (SMS-RJ, 2010). ${ }^{4}$

Desde os anos 70, a gravidez na adolescência vem se construindo como uma preocupação na América Latina, resultando na proliferação de trabalhos de pesquisa e discursos diversos. Como lembra Heilborn (2006), a construção desse fenômeno como "problema social" estava ligado à "ilegitimidade" dessas gravidezes fora de uma união. Em geral, esses trabalhos demonstram a importância da maternidade na formação da identidade feminina, especialmente em áreas populares, com foco em uma socialização feminina que prescreve a maternidade para as jovens, ou contrariamente com foco na falta emocional que a gravidez iria preencher. Porém, novas expectativas sociais se desenham para as jovens mulheres e a gravidez na adolescência torna-se um problema na realização pessoal, no que concerne ao nível escolar e profissional. A socióloga Johanne Charbonneau (1998) diz a este respeito que a maternidade adolescente é considerada tanto "causa" de uma posterior trajetória "a problemas", no nível familiar, profissional e escolar, quanto "consequência" de uma série de dificuldades que a jovem mãe tem vivido desde a infância, aproximando-se assim de explicações de tipo psicossocial, nas quais a "falta de diálogo com os pais", a falta de autoridade, ou a "banalização da sexualidade" são mobilizadas como causas desse desfecho. Bajos e Ferrand (2006) postulam a existência de um universo normativo que elas chamam de "norma procriativa contemporânea" - definindo a idade certa para a procriação, o espaçamento

\footnotetext{
${ }^{4}$ Outros dados da SMS mostram que 33\% das mulheres que tiveram filhos em 2010 tinham sete ou menos anos de escolarização, que $92,65 \%$ dos nascimentos foram conveniados pelo SUS e que a grande maioria aconteceu num hospital municipal.
} 
dos nascimentos, o planejamento das gravidezes, as práticas anticonceptivas institucionalizadas etc. - atingindo as mulheres mais jovens por diferentes canais, como a mídia, os grupos de pares, a família e as instituições escolares e de saúde. Essa normatividade geral é vivenciada diferencialmente segundo marcadores como classe social e gênero, inseridos em trajetórias e itinerários diferenciados, como temos dito.

No processo de institucionalização do "problema social" observa-se um deslocamento da gravidez na adolescência para um "problema de saúde", ligado fundamentalmente à medicalização da gravidez, em que os médicos serão os primeiros a mobilizar-se sobre esse tema a partir de argumentos biomédicos (Heilborn, 2006). Tal como avalia Brandão (2006), o enfoque "sociocultural" disputa com o "enfoque de risco", que ganhou terreno nas últimas décadas na questão da gravidez na adolescência.

As perspectivas epidemiológicas sobre o fenômeno parecem ganhar força estabelecendo causalidades que já não tangem somente a "mãe", mas que incorporam uma série de previsões sobre a saúde da futura criança (baixo peso ao nascer, mortalidade neonatal etc.). Nesse sentido, a preocupação médica esconde certa estigmatização de modelos reprodutivos diferentes e do caráter sociocultural e histórico das idades e das expectativas sociais que lhe são atreladas (Heilborn, 1998).

Vários trabalhos (Heilborn, 2002; Brandão, 2004; Bajos, Ferrand e Giné, 2002; Bajos e Ferrand, 2006) mostram as sucessivas construções estereotipadas da maternidade na adolescência. Atualmente, caracteriza-se esse tipo de gravidezes como sendo uma "maternidade de risco" (Faya Robles, 2014), nas quais se produz uma superposição entre o risco biológico e a representação de uma relação materna que precisa ser reeducada, tal como veremos em seguida.

A partir do momento em que a "maternidade precoce" transforma-se em um "problema de saúde", ele entra na agenda e no planejamento de políticas públicas. Há vários anos, desenvolve-se um modelo de atenção à saúde do jovem e do adolescente, integrado ao marco do Sistema Único de Saúde, Lei 8.069/90, tomando como princípios e diretrizes aqueles do Estatuto da Criança e do Adolescente (ECA), o qual prevê a implantação de políticas públicas referentes à juventude. No entanto, diferentes campos, como a medicina, a demografia e a educação, articulam-se com o intuito de gerir a sexualidade adolescente a fim de, entre outros, evitar a gravidez, que aparece como o "problema maior" a ser evitado, o que resulta em várias ações intersetoriais, ligando, por exemplo, saúde e educação. Porém, as etnografias revelam a fraca efetividade desses programas, sendo identificada a Estratégia de Saúde da Família (ESF) como única instância que deve se ocupar da saúde das jovens. 
Assim, diante da falta de outro tipo de políticas englobantes da saúde dos jovens, as práticas cotidianas das equipes da ESF levam a um funcionamento em que as próprias lógicas de atuação produzem uma segmentação dos usuários. Essas lógicas, fortemente influenciadas pela obrigação de produtividade e produção de certos indicadores por cada equipe, mas norteadas também por percepções estereotipadas dos jovens e das relações de gênero, produzem disparidades em termos de acesso e de cuidado, incluindo, às vezes de maneira constrangedora, certas categorias e limitando-os a outras.

Dentro da categoria dos jovens, a subcategoria das jovens grávidas se destaca. Se a "maternidade na adolescência" aparece como "o problema" dos jovens, na visão dos profissionais, eles priorizam o atendimento às "adolescentes grávidas" como uma subcategoria idealizada dentro do grupo de jovens. Produz-se, assim, não somente uma invisibilização dos meninos nos processos reprodutivos, como também o de outros problemas de saúde nos jovens como a violência, as práticas de risco, o consumo de drogas, a falta de direitos sexuais e reprodutivos, entre outros. Cria-se também um fenômeno segundo o qual somente as jovens grávidas teriam a legitimidade para serem usuárias do serviço.

A expansão do campo da saúde materno-infantil na esfera pública, a partir da extensão do SUS e do Programa Saúde da Família, está atrelada ao processo de medicalização da gravidez (Costa et al., 2006; Chazan, 2007), modificando as formas de lidar com fenômenos fisiológicos, modulando novos saberes e percepções do próprio corpo (Jacques, 2007). Em suma, modificando culturalmente (Tesser, 2006) as maneiras como as mulheres experimentam esses processos.

Porém, temos observado que a esfera da saúde esta atravessada por paradigmas diversos, que se transformam, ao seu turno, em novas práticas e saberes, assim como em novas regulações. No campo da saúde materno-infantil brasileiro, as imbricações entre um modelo medicalizado e um modelo "humanizado" (Tornquist, 2002) aparecem como o contexto no qual conflitos e arranjos se produzem constantemente nas experiências. Estes dois processos, medicalização e humanização, interagem constantemente e, por exemplo, enquanto as mulheres que dão à luz em clínicas particulares são aquelas que experimentam a maior taxa de cesarianas (Víctora et al., 2011), as mulheres que dão à luz nos serviços públicos têm acesso limitado a certas técnicas limitadas pelas políticas de humanização, como é o caso da cesariana (Faya Robles, 2008; Denyer, 2009).

De fato, o processo de humanização poderia ser contido em um processo mais amplo de "sanitarisation", produzindo efeitos de regulação nas mulheres. O processo de sanitarisation - ou "helthnisization" (Conrad, 2007) - refere-se à onipresença e à supremacia do valor "saúde" em sentido amplo, não somente 
biomédico, mas segundo uma "definição positiva" (Camargo, 2013), quer dizer, não como ausência de doença ou de complicações, mas postulando a saúde como uma "autorrealização" de si (Clarke et al., 2000). ${ }^{5}$

O pré-natal, tal como é implementado nos dois contextos de pesquisa, aparece, então, como um dispositivo de regulação segundo o qual as jovens mulheres de camadas populares deverão desenvolver cuidados para si e para o "outro", cuidados que não somente abrangem a dimensão biológica e corporal, mas também derivam na construção de um papel parental particular. Veremos em seguida como se desenvolvem algumas técnicas de regulação que puderam ser observadas nos dois campos de pesquisa e que se situam, a nosso ver, no cruzamento entre a medicalização e a sanitarização, atuando como tecnologias específicas de individualização das gestantes.

\section{A assignação materna: do estar (grávida) ao ser (mãe).}

A eficácia na afluência precoce e na assiduidade das mulheres nas consultas pré-natal, como atestam os dados apresentados anteriormente deve ser associada a várias ações do dispositivo de saúde nessa direção, como a consolidação da Atenção Básica de Saúde ou a Rede Cegonha. Outras medidas menos explícitas do que as formuladas nos programas e políticas de saúde foram, entretanto, observadas também. Uma das prerrogativas dessas ações é a vigilância meticulosa - realizada pelas enfermeiras e pelos agentes comunitários de saúde das unidades de Programas de Saúde da Família - para a rápida captação das mulheres grávidas nos territórios observados. Assim, os dois principais objetivos para as agentes comunitárias de saúde definidos pelo Ministério da Saúde através do manual técnico de pré-natal são: 1) captar gestantes não inscritas no pré-natal; 2) Reconduzir gestantes faltosas ao pré-natal, especialmente as de alto risco (Brasil, 2010).

Chamamos de assignação ${ }^{6}$ à maternidade a velocidade com que o dispositivo de saúde "descobre" os casos de gravidez. Os agentes comunitários

\footnotetext{
${ }^{5}$ Para uma utilização mais operativa mobilizamos a tipologia de Hislop e Arber (2003): a medicalização faz referência às formas de compreensão dos fenômenos a partir do registro da doença e da tecnologia, ao passo que a sanitarização mobilizaria o registro do bem-estar psíquico e físico para explicar situações e fenômenos fisiológicos.

${ }^{6}$ Utilizamos o neologismo "assignação" numa perspectiva próxima de Judith Butler, que reconstrói a noção de "interpelação", de Louis Althusser, segundo a qual o indivíduo torna-se sujeito pela interpelação - "eh, você, lá" - ideológica e policial. Para Butler (2004), não somente se trata de uma designação unilateral, policial e definidora dos sujeitos, mas também há, do lado do sujeito, um desejo de inscrição em "um lugar" social. Além disso, na perspectiva de Butler, a assignação não é reproduzida identicamente, mas no investimento subjetivo da repetição (da posição social, do papel assignado) se produz um movimento de recriação, um deslocamento introduzido pela própria iteração.
} 
de saúde representam um ator importante nesse trabalho de despistagem (no sentido médico de procurar sinais e pistas) de gravidezes nos bairros, justamente pela posição de mediação entre os moradores e os serviços de saúde e pela participação deles nas relações de sociabilidade nos territórios onde certas informações de ordem privada circulam no espaço público e onde a "familiaridade" e a "fofoca" voltam-se um recurso profissional para os agentes comunitários de saúde (Faya Robles, 2012).

A filha de Gégé (18 anos) pede à ACS [agente comunitária de saúde] uma consulta ginecológica no posto. A ACS exclama-se "Ah! minha filha, faz quanto tempo que você não teve a menstruação?" A menina constrangida responde que faz dois meses, mas ela argumenta que deve ser por conta do estresse, que ela começou faz pouco tempo a trabalhar e que ela tem certeza que ela tem um cisto. A ACS ironiza "Ah! que lindo... se é menino é Cisto, se nasce menina é Miasma?" (Diário de campo, Recife, 2008)

Uma vez que a gravidez é "captada" e confirmada pelos profissionais de saúde, a mulher é assignada como mãe - ela passa a ser chamada de mãezinha nos serviços de saúde - e ela é registrada para realizar consultas pré-natais. Além disso, a frequência mensal das visitas, o registro da gravidez nas unidades básicas do Programa de Saúde da Família e no sistema de monitoramento nacional do pré-natal, conferindo um cartão de identificação da gestante (e no SIS-prénatal), trabalham, também, nessa lógica de assignação, como "tecnologias individualizantes" (Rose, 2011, p. 143), conferindo uma "identidade" à mulher. Assim, numa reunião de gestantes numa Clínica da Família do Complexo do Alemão, a primeira pergunta da enfermeira é se elas já têm o "cartão de gestante", que ela diz ser "como o passaporte de vocês [...] assim não precisam andar com todos os documentos para todo lado [...] ali constam as vacinas, os controles, os exames [...]". O cartão de gestante, assim como a carteira de identidade, produz uma pessoa a partir das diferencias que tem com as outras pessoas. A função é a de dissociar, utilizando diversos parâmetros de identificação (idade, foto, endereço etc.) para atestar diferenças. Funciona, assim, como um instrumento de controle (número de consultas, testes realizados etc.) que põe em uma relação assimétrica a mulher e uma autoridade (médica, hospitalar, assistencial etc.).

A assignação é impelida nos contextos estudados onde agentes comunitários de saúde e outros profissionais devem trabalhar nessa descoberta dos casos de gravidez. A fala de uma enfermeira do posto de saúde em Recife mostra não somente a meta de rápida absorção de qualquer mulher que apresenta 
sinais de gravidez, mas também a existência de certa resistência por parte das mulheres em entrar imediatamente no circuito que a define apressadamente como "mãe":

Às vezes, algumas (mulheres) chegam bem precocemente. Assim, a menstruação atrasou e elas vêm; mas outras não, a maioria deixa passar dois ou três meses pra dizer à agente de saúde que tá sem menstruar. Uma chegou agora, uma mulher que a gente acompanha no pré-natal, que já faz dois meses que não menstrua. Aí eu solicitei um beta (teste) pra vê, pra já iniciar o pré-natal. É assim, depende... tem aquelas que têm resistência ao pré-natal, aí, não faz muita questão de descobrir logo, de falar logo, entendeu. Mas a gente tenta buscar o mais precocemente possível com os agentes de saúde, né.

A urgência com que as gestações são inseridas no circuito da saúde materno-infantil dificulta às mulheres considerarem uma interrupção da gravidez ou até mesmo a saída do circuito de regulação. Porém, o processo de "assignação" à maternidade não deve ser visto como ato implacável e unilateral. Nesse sentido, a "assignação à maternidade" não revelaria a existência de um dispositivo disciplinar foucaultiano. A assignação se apresenta difusamente por duas razões: não só o emissor do convite para "tomar" um papel social não é uma figura identificável e permanente, a partir de instituições sólidas de controle social, nem o "convite" para "ocupar um lugar" é necessariamente repressivo. Ele encontra a sua resposta em certo desejo por parte das mulheres jovens de camadas populares de encontrar uma posição social através da maternidade (Dadoorian, 1996). Nesse sentido, não somente o acesso a determinadas posições e funções sociais (pelo trabalho ou a escolaridade) é objetivamente reduzido, mas essa limitação atua no nível subjetivo por uma delimitação do possível porvir. Uma agente comunitária de saúde de Recife vê a impossibilidade subjetiva para as mulheres de considerarem outras posições sociais: "Muitas delas começam aos 12, 13, 14 anos a namorar... Não fazem curso fora, porque eu acho se elas fazerem um curso fora, isso dá outra visão, fora do bairro, acho que elas não ficariam assim (grávidas) [...]”.

Contudo, a outra face da moeda da assignação da mulher grávida como mãe e sua captação para o pré-natal é a invisibilidade das outras mulheres jovens que chegam nas unidades de saúde. Um exemplo paradigmático dessa concentração das mulheres jovens nas suas únicas qualidades de "futuras mães" - observada tanto no Recife como no Rio de Janeiro - é a incapacidade de absorção pelos serviços de meninas que chegam para realizar um teste de gravidez e que "desaparecem" e não são acompanhadas pela equipe quando o resultado do teste se revela negativo. Como relata uma enfermeira: "Aqui 
tem muitas gestantes que vêm fazer o teste de gravidez e logo desaparecem". As instâncias preocupadas na prevenção da "gravidez na adolescência" encontram práticas contraditórias, de invisibilização das jovens que chegam espontaneamente nos serviços para tirar dúvidas sobre uma possível gravidez. Assim, a lógica de prevenção e promoção de uma saúde reprodutiva, no sentido amplo para os jovens, vê-se destituída na prática pelas lógicas de assignação materna e de centralidade do pré-natal.

\section{A formação de um "projeto de criança"}

Durante as consultas do pré-natal a mulher será solicitada a desenvolver um "projeto de criança". Para isso, o dispositivo desenvolve técnicas de regulação dos corpos que tendem a individualizar a experiência da gravidez e supervalorizar o substrato biológico da relação de filiação e da maternidade, encorajando a construção de formas sanitarizadas de relacionamento consigo mesma. O dispositivo procura construir um "projeto de criança" individual e incorporado em mulheres jovens de camadas populares, cujas lógicas de recebimento da criança são um pouco diferentes e implicam uma rede de apoio.

Nós nos apoiamos aqui na abordagem de Boltanski na sua "sociologia da procriação", segundo a qual a experiência da mulher, aqui sua experiência da "carne", se define como a "maneira como elas (as mães) sentem [...] na sua carne, o encontro entre os componentes e as determinações da ação" (Boltanski, 2004, p. 17). Quer dizer, como se constroem os arranjos simbólicos para a difícil tarefa de conversão do que, inicialmente, são apenas modificações fisiológicas que a mulher sente no corpo, para a confirmação de uma "gravidez" e a transformação do ser que cresce no ventre em um "ser de carne", em "ser de palavra" não-intercambiável com outro. Como Boltanski na França, encontramos em nossas interlocutoras brasileiras a necessidade de arranjos simbólicos para a decisão, que recai em última instância sobre a mulher, de construir um "acidente de contracepção" (Boltanski, 2004) em uma gravidez. O uso de legitimação religiosa ("Deus o quis assim!"), que vem acompanhada da recusa de aborto, ou a referência ao pertencimento a uma comunidade moral ou à solidariedade familiar (“Onde comem dois, comem três!”) foram os tipos de arranjos mais recorrentes na confirmação da gravidez de mulheres mais velhas ou das que já tinham filhos. Nas mulheres jovens e adolescentes, esses tipos de arranjos simbólicos, que poderíamos chamar de "tradicionais", estão sendo substituídos por outro. Nessas mulheres, a legitimação do feto parece ter-se transferido para a esfera do indivíduo e toma como referencial de legitimação a forma de "projeto de criança" (Boltanski, 2004) como projeto individual, ligado a certa visão de realização pessoal. 
É justamente na emergência desse tipo de arranjo que os serviços de saúde cumprem um papel importante. Pois, se efetivamente há uma "assignação" difusa que leva as jovens mulheres a entrarem cedo no ciclo materno, geralmente não há um "projeto" preexistente, como pode ser a modalidade do planejamento da gravidez. Nesse panorama, o aborto e a "descida de regras" fazem parte das possibilidades das mulheres, segundo lógicas relacionais e situacionais que as levam a "assumir" ou não uma gravidez (Leal e Lewgoy, 1995; 1998). Nesse sentido, o fato dos serviços de proximidade "saberem" precocemente da gravidez e assignarem a mulher como "mãe" limita esse jogo estratégico entre o assumir e o não assumir, incitando a mulher a construir um "projeto de criança". Bajos e Ferrand (2004) salientam para o contexto francês: todo nascimento deve ser desejado e programado, mas o direito de decidir o momento de ser mãe acompanha-se ao mesmo tempo de uma pesada responsabilidade de fazer essa escolha. Porém, no contexto brasileiro de proibição do aborto e de limitação desse direito de decisão, a assignação à maternidade e a solicitação de construir um projeto tomam uma coloração particular.

No entanto, o "projeto de criança" e o planejamento familiar não se enquadram no padrão de procriação das mulheres jovens de baixa renda. Como disse uma jovem de Recife: "Queríamos filhos, mas nunca planejou.". Dito de outra maneira, as jovens dificilmente se encaixam dentro do que Bajos e Ferrand (2006) chamam de "norma procriativa contemporânea", em que o ser a nascer deve ser "desejado" e "planejado". Os dados da Pesquisa Nacional de Demografia e Saúde da Criança e da Mulher, de 2006, mostram que nos últimos 5 anos as mulheres menores de 20 anos que tiveram filhos e que "queriam agora" representam $45 \%$, enquanto as que queriam mais tarde ou não queriam representam 57,7\%.7 Geralmente, nas mulheres mais novas se constrói o "projeto de criança" a posteriori, depois da procriação. O dispositivo é assim relegado a intervir depois da procriação, quando a gravidez foi "captada" pelos profissionais de saúde e inscrita no pré-natal e a mulher assignada como mãe.

Aí fiquei (grávida), né? Aí fui fazer exame. No dia que eu fui fazer exame acusou que eram gêmeos, aí fiquei nervosa também porque eu não esperava né? [...] Mas o médico conversou muito comigo, disse que era melhor que fosse bebê do que doença [...] aí eu fui me acalmando, né? Ai pronto! (Entrevista, Rio de Janeiro, 2013)

\footnotetext{
${ }^{7}$ A Pesquisa Nacional de Demografia e Saúde da Criança e da Mulher (PNDS) do Ministério da Saúde revelou para o conjunto de mulheres em idade fértil que $53,9 \%$ das gravidezes de mulheres brasileiras foram planejadas e $45,8 \%$ não foram planejadas para aquele momento ou foram indesejadas (Berquó e Lima, 2006), mostrando um diferencial nas mulheres mais jovens.
} 
É durante o pré-natal que o projeto deve ser construído. Trata-se de uma nova área de intervenção para os profissionais de saúde, que deverão monitorar a construção desse projeto e avaliá-lo a partir de uma série de parâmetros: "planejamento" da gravidez, comportamentos da gestante, assiduidade nas consultas do pré-natal, "aceitação" da gravidez, ${ }^{8}$ e até a escolha do nome para o futuro neném. Como relatou a psicóloga de uma maternidade de Recife: "Quando você vê um bebê sem nome eu me preocupo muito. Qualquer mãe que estava aqui sem nome para o bebê, você pode adiantar que tem alguma coisa ruim naquela relação $[\ldots] "$ ".

A relação da mulher com o ser dentro de seu corpo deve começar durante a gravidez, e essa confirmação do "ser de palavra" deve ser observada pelos profissionais de saúde. Assim, vemos como a falta de nome para o bebê, por exemplo, vem objetivar a apreensão da rejeição da gravidez que levaria necessariamente, segundo o imaginário do dispositivo de regulação, a uma rejeição da criança.

Porém, tal como o fato de "assumir" a gravidez, a construção do "projeto de criança" possui uma lógica relacional para as mulheres. Por exemplo, nas práticas de nominação das crianças observamos que as mulheres seguem uma lógica criativa e situacional, ligada fortemente aos diversos estágios de sua rede social durante o processo de gestação da criança. Assim, por exemplo, Priscila (17 anos), que no início da gravidez ainda estava com o namorado, dizia: "Se for homem, vai ser a mãe dele quem vai escolher, se for mulher vai ser a minha família quem vai escolher. Então está certo, tomara que seja menina". Dois anos depois, quando voltamos a falar com ela, as relações de sua rede tinham mudado em decorrência da separação do namorado, e o "projeto" assim como a nominação da criança tinham se adaptado à nova configuração de sua rede de apoio. Finalmente, foi a mãe de Priscila quem deu o nome à criança: "Não tive mais contato com ele (namorado), tive minha mãe pra ela (a criança) [...]". Vemos que, contrariamente ao que o dispositivo pretende na singularização do projeto, ela depende menos de uma individualização da experiência da gravidez do que da inserção dela em uma rede de apoio, a qual pode ir mudando no transcurso da gestação.

\section{Integrar um "grupo prioritário": a regulação pela palavra}

Devido ao foco na prevenção de complicações e promoção de saúde estar centrado em visitas domiciliares regulares, a Saúde da Família visa a acessar

\footnotetext{
8 A importância dada a essa "aceitação", "desejo" e "planificação" - os quais aparecem como sendo similares nas representações dos profissionais - é manifesta no "cartão da gestante" nos serviços do Rio de Janeiro, em que o quesito "a gravidez foi planejada?"é uma das primeiras perguntas feitas às mulheres.
} 
grupos populacionais pouco visíveis em outras estratégias da Atenção Básica, dentre os quais, adolescentes e jovens. Essa ausência não só aparece como desinteresse dos jovens pela própria saúde, mas também como decorrente de certas lógicas institucionais dos serviços, que não cobrem as especificidades dos jovens. Eles não formam o "fluxo" de demandas para o atendimento dos serviços e não constituem um "grupo" prioritário para as equipes. Apesar de grupos de jovens serem preconizados pela Secretaria Municipal de Saúde do Rio de Janeiro, na unidade estudada no Complexo do Alemão, havia dificuldade de realização desses atendimentos.

Diferentes lógicas institucionais em um contexto de expansão e de reorganização dos serviços de saúde, como é o caso do Complexo do Alemão, produzem efeitos de inclusão e exclusão de algumas categorias dentro do mesmo grupo populacional. No caso das adolescentes, elas tornam-se sujeitos priorizados pelo cuidado quando passam para outra categoria social: a de mães. Existe uma importante prática de formação de grupos de gestantes para o pré-natal, tanto em Recife como no Rio de Janeiro. Adriana (19) conta que, ao confirmar a gravidez, buscou o posto de saúde mais próximo, tendo sido encaminhada para a Clínica da Família, onde participou do grupo de gestantes e se inscreveu "num projeto" dedicado a mães e bebês, o projeto Cegonha Carioca: “[...[mas, aí, a Cegonha já é só mesmo pra gestante [...] entendeu?”.

A formação de grupos é um objetivo fundamental na atenção básica, o que repercute fortemente dentro da esfera da saúde materno-infantil. Assim, é interessante notar que, tal como o Ministério da Saúde recomenda, as "discussões com e entre mulheres" tornam-se um instrumento de regulação fundamental dentro do dispositivo sanitário. Isto é o que Dominique Memmi (2003) chama de "governo pela palavra", situação em que a "escuta" torna-se o dispositivo que procura fazer com que a mulher produza um discurso legítimo sobre a relação com seu corpo, com a gravidez e com a futura criança. É também o campo da intervenção que muda, e já não é somente o corpo em si, mas o corpo posto em discurso que deve ser regulado a partir "da palavra" (Memmi, 2003).

As "discussões entre mulheres", como o grupo de gestantes nos postos de saúde, tornam-se o epicentro para a transmissão de normas. Assim, além das consultas que põem em relação médico e paciente, típicas do que se chama de processo de medicalização, a formação de grupos aparece como momento fundamental no qual cristaliza-se a transmissão de normas corporais e parentais sob o registro da sanitarização. Durante esses encontros, as atividades médicas são menos importantes que o controle dos discursos sobre as condições familiares, de higiene e do conforto físico e mental na gravidez. 
No grupo de gestantes na Clínica da Família no Complexo do Alemão, a enfermeira começa perguntando se todas têm o "cartão de gestante". Depois a fala se direciona ao aleitamento materno:

Tem que beber muita água, fazer lanche a cada três horas para manter a energia do corpo, pois o aleitamento pega toda a energia. Mas, não é para comer feijoada cada três horas. Nem café, nem álcool, claro! $[\ldots]$ tem que pensar que a alimentação não é só pra vocês, mas é para o neném também.

As conversas não se desenvolvem somente no registro fisiológico e sobre a gravidez, abrangendo todo o corpo da mulher, que vê-se circunscrito à função materna. Assim, as práticas estéticas das mulheres devem ser limitadas: "Silicone, piercing, tatuagens são a evitar, pois temos menos imunidade, pois o corpo está concentrado na gravidez e o aleitamento". As agentes comunitárias de saúde e as enfermeiras em Recife aconselham as mulheres a "fazerem massagem como os ricos", "tomar banhos de sol" para "viver uma gravidez bonita". Porque, como diz uma agente comunitária de saúde: "tem que amar a si mesmo para poder amar outra pessoa".

Assim, esses encontros incentivam as mulheres a sentirem o corpo como um corpo que contém um "outro", e a construir a partir do corpo materno e do feto uma unidade experiencial, em que a mulher possa sentir por ambos. As práticas de alimentação, de cuidado de si etc. são orientadas no cuidado do "outro". Mas esse cuidado não se restringe à saúde; ele abrange também a educação da criança e a relação parental. A enfermeira diz: "A educação começa agora na gravidez não quando a criança começa a falar, ele vê tudo [...]; se ele vê a mãe comendo no McDonald's, vai querer também".

$\mathrm{Se}$ as conversas entre mulheres são tipicamente uma via de transmissão de normas relativas à maternidade, o que aparece como original nos contextos estudados é o fato de que essas conversas são promovidas e mediadas pelo saber médico e sanitário e pela instituição de saúde. Durante um grupo, a fala de uma enfermeira é explícita: "cuidado porque tem sempre essa história de que uma vizinha me falou que o chá foi muito bom, que ele conseguiu não sei o que ...; mas o que funcionou pra ela não vai funcionar em vocês". Assim, longe de uma construção comum das experiências, o dispositivo do grupo funciona como uma técnica de individualização das experiências, em que as mulheres vão construindo um relato de si - "para mim foi assim", "eu tive muito enjoo" etc. - os quais não alcançam a construção de uma "comunidade de experiência", nem de uma politização do vivido. 


\section{A "gravidez de risco" das mulheres jovens}

No dispositivo do pré-natal é fundamental a importância que recobre a noção de risco para a gestão das gravidezes. Como lembram as autoras Corrêa e Guilam (2006, p. 42): "Por meio do discurso biomédico, a mulher grávida se vê cercada, hoje, de uma rede de vigilância de seu corpo, passando a ser responsabilizada não só pela própria saúde, mas também pela produção de um feto saudável. Por tudo isso, o pré-natal é um lócus privilegiado do discurso de risco".

Em 2000, o Ministério da Saúde do Brasil distribuiu para profissionais e autoridades de saúde pública o primeiro manual para a gestão da gravidez, no qual a intervenção vai distinguir "desde o mínimo, para os indivíduos sem problemas ou com poucos riscos de oferecerem danos, até o máximo necessário para aqueles com alta probabilidade de sofrerem agravos de saúde" (Brasil, 2000). O Ministério da Saúde identifica quatro tipos de fatores de risco: o primeiro, e mais problemático na prática, é aquele das chamadas características individuais e condições sociodemográficas desfavoráveis, no qual são considerados a idade da mulher (menor de 19 anos e maior de 35); os fatores de risco relacionados com a história reprodutiva da mulher; as doenças obstétricas aparecidas durante a gravidez e, finalmente, o quarto grupo de fatores de risco ligado à história clínica da mulher.

Longe de ser uma categoria "desencarnada" (Calvez, 2001, p. 127), o risco funciona como um recurso cultural através do qual o dispositivo de saúde procura prescrever normas de conduta desejáveis a grupos-alvo. Assim, a categoria de "alto risco", quando definida pelos serviços locais a partir de fatores demográficos, aplica-se, sobretudo, para adolescentes grávidas que parecem reunir outros fatores de risco que fazem parte da lista, como o "casal instável" ou "a rejeição da gravidez". As jovens seriam mulheres que não reproduzem o modelo idealizado da família nuclear das camadas médias, nem entram na "norma procriativa contemporânea" (Bajos e Ferrand, 2006). Nas palavras dos profissionais de saúde, estas mulheres têm: "as famílias completamente desestruturadas" (Diário de campo, Recife, 2008). Assim, fenômenos sociais como o da "maternidade na adolescência" ou fenômenos médicos, como as reais dificuldades fisiológicas nas meninas mais novas, são englobados numa mesma categoria sanitária.

Essa designação das mulheres mais jovens na categoria das gestações de risco está arraigada no pressuposto dentro da saúde pública de uma ligação causal entre "gravidez na adolescência" e "mortalidade infantil" (Katz, 1999; Martins e Heilborn, 2006). Sendo este último fenômeno um imperativo dos 
órgãos sanitários, podemos inferir o encaminhamento das mulheres jovens para serviços de alto risco.

No entanto, reunir sob o nome de "gravidez na adolescência" todas as gestações de mulheres jovens (com base na definição da maioridade civil) produz dois efeitos contrários. O primeiro é a invisibilização dos riscos "reais" e os altos percentuais de problemas nas gestações em faixas mais jovens desse grupo (menores de 15 anos); por outro lado, se faz um controle excessivo nas jovens mais velhas. A consequência da homogeneização e da objetivação pela formação desse grupo que será vigiado é paradoxalmente a imprevisão dos riscos fisiológicos. Assim, se se divide o grupo em duas faixas etárias, encontramos taxas de mortalidade infantil muito dispares. Em 2006, no Recife, para meninas de 10 a 14 anos há uma taxa de mortalidade neonatal de $40 \%$, enquanto entre as jovens de 15 a 19 anos a taxa de mortalidade infantil foi de apenas 8,5\%, uma taxa menor do que a observada em mulheres com mais de 20 anos (10,24\%) (Scott, 2007). Assim, o discurso sobre risco se aplica desnecessariamente a um grupo que não apresenta riscos biológicos a priori, respondendo a outras exigências, menos médicas e mais culturais. Como sugere Marcel Calvez (2001), a categorização social a partir do risco moraliza o perigo, ligando-o à construção de uma comunidade. Trata-se aqui da construção de uma comunidade de mães pobres, que entram muito jovens no ciclo materno e seguem modelos reprodutivos "diferentes" e, portanto, de risco.

Por outro lado, obscurecem-se os riscos das mulheres mais velhas (tanto os fatores sociodemográficos, quanto os clínicos ou fisiológicos) e aqueles relacionados com o genitor, criando disparidades de tratamento em relação à idade e ao sexo. Riscos relacionados com o "pai" são eclipsados pela formulação da unidade mãe-filho como unidade fundamental do cuidado sanitário. Assim, por exemplo, nas primeiras consultas do pré-natal, e com o objetivo de preencher o "cartão de gestante", são feitas perguntas relativas à existência de possíveis doenças hereditárias da família materna. Jamais são questionados possíveis antecedentes da família paterna, reforçando o distanciamento já existente dos homens jovens com os serviços de saúde (Scott, 2007, p. 4).

A categoria "objetiva" de risco cumpre uma função fundamental na assignação à maternidade, reduzindo as possibilidades da gestação resultar em um aborto. Uma enfermeira de Recife afirma: "Se adolescente engravidar é de risco [...] porque muitas vezes não tem apoio e termina abortando a criança". O risco vai então além das condições fisiológicas da gravidez, e uma "gravidez de alto risco" pode tornar-se em "maternidade de risco" não a 
partir do ponto de vista clínico, mas do relacional (Faya Robles, 2014). Nesse sentido, o seguimento mais sistemático das gravidezes de risco participa da lógica de construção do projeto de criança, produzindo um acréscimo das responsabilidades parentais nas mulheres jovens. Assim, uma mulher de 17 anos de Recife diz:

Mesmo se não era de risco, ser mãe de risco foi para mim uma experiência muito boa porque aí tive mais responsabilidades. Me tornei mais responsável por mim e pela minha filha. [...] Lá, nos serviços de alto risco, nos fazem compreender, às mães de alto risco, que temos mais trabalho pra fazer para proteger a criança.

Ser mãe de "alto risco" funcionaria como um excedente do papel materno delegado aos cuidados diversos, tarefas e atenção com a criança (care), apelando a um acréscimo da responsabilidade individual para com a saúde e a vida do feto. Procura-se criar uma "biopolítica delegada" (Memmi, 2004) aos indivíduos na gestão dos perigos associados à própria saúde e à do feto. Assim, o "risco" na área da saúde materno-infantil transcende o próprio campo da saúde para criar normativas - sanitarizadas - no seio da família e mais especificamente no laço parental mãe-filho. A categoria "objetiva" de risco torna-se um operador sanitarizado de "personalização" da gravidez, procurando a socialização das adolescentes na autorregulação de seus corpos e de seus comportamentos maternos.

\section{As experiências das jovens: entre adesão, estratégias e autonomia}

As novas políticas de saúde reprodutiva operam através da mobilização de categorias culturais características de um individualismo de novo corte. Com a classe média como modelo, a representação da vida contemporânea em termos de "escolhas" e liberdade individual recolhe certa adesão das mulheres jovens de camadas populares, graças à força integradora dos meios de comunicação de massa e das técnicas do dispositivo sanitário que conforma através do pré-natal e que procuramos descrever aqui. Culto de um corpo subjetivado pela palavra, bem-estar na gravidez, individualização do projeto de criança, criação de espaços de discussão, transmissão de categorias sanitárias - neste artigo buscamos desenhar os contornos de um mundo popular aberto e pronto a aderir a essas novas categorias. Não obstante, identificamos "táticas", no sentido empregado por De Certeau (1990), implementadas pelas mulheres para contornar alguns dos constrangimentos advindos do dispositivo de saúde e que lhes permitem construir uma experiência própria da maternidade. Nesse 
sentido, a adesão não é disciplinamento e a reprodução inclui bifurcações nas experiências.

Assim, a assignação à maternidade do dispositivo lida com as possibilidades abertas pelas táticas do "dizer ou não dizer", “esconder ou não esconder" a gravidez. Observamos, nesse sentido, como as mulheres jovens desenvolvem estratégias temporais e relacionais que freiam a autoridade do dispositivo na assignação à maternidade.

Em relação ao "projeto de criança", observamos inflexões na construção das mulheres. Não apenas ele se constrói após a procriação, como dito anteriormente, mas também é feito coletivamente. O "projeto de criança" não é um projeto individual, ele se constrói na medida das possibilidades abertas pela organização doméstica e pela rede das mulheres.

A técnica do dispositivo que procura apostar em um "discurso" do corpo não é sempre bem sucedida e só funciona dentro de determinadas condições, quando esse registro pode sustentar-se nas relações sociais e não apenas em um corpo individualizado. A sanitarização da percepção interna incentivada pelo dispositivo de saúde é articulada com uma percepção relacional, em que as pessoas da rede propõem modelos alternativos na construção da experiência da gravidez.

Há muitas vezes uma discrepância entre a assignação institucional de uma "gestação de risco" e a percepção do risco nas mulheres. Assim vimos, no trecho da fala de uma jovem mãe de Recife, que ela dizia: "mesmo se eu não era realmente de risco, ser mãe de risco foi para mim muito bom". Esse "realmente" manifesta o fato de que ela não via a si mesma como "de risco"; embora tenha sido assignada dessa maneira, sua percepção interna não se identifica completamente com o registro sanitarizado; e a assignação é vivenciada como uma etiqueta que não é completamente incorporada. Por outro lado, a experiência da gravidez é uma experiência relacional que se constrói na rede primária das mulheres e em especial entre as mulheres que vivem uma gravidez "de risco", na qual há mais responsabilidades para assumir e recorre-se com maior intensidade à rede de apoio.

As técnicas do dispositivo de saúde procuram responsabilizar as mulheres mediante a individualização da experiência da gravidez através de categorias sanitárias cada vez mais personalizadas, como a noção de projeto ou de risco. Mas estas técnicas nem sempre são operacionais na prática. Isto é fundamental para atenuar a força de influência do dispositivo sobre a experiência da maternidade, pois longe de se tratar de um dispositivo disciplinar que impõe a subordinação do indivíduo a uma autoridade superior (a racionalidade científica da medicina, ou as necessidades sanitárias da saúde pública), em detrimento de 
qualquer aspiração a um bem-estar individual, a eficácia do dispositivo enquanto instrumento de governo baseia-se cada vez mais no princípio de colocar, ao menos idealmente, o indivíduo, sua liberdade e suas escolhas, no centro da construção das políticas de saúde. Uma vez o "individuo" idealizado no centro do dispositivo de saúde, falta que as novas tecnologias na saúde maternoinfantil levem em conta as reais configurações que toma a individualização das experiências das mulheres jovens de camadas populares.

\section{Referências}

BAJOS, Nathalie; FERRAND, Michelle; Equipe GINÉ. De la conception à l'avortement: sociologie des grossesses non prévues. Paris: Inserm, 2002.

BAJOS, Nathalie; FERRAND, Michelle. La contraception, levier réel ou symbolique de la domination masculine? Sciences Sociales et Santé, v. 22, n. 3, p. 117-142, 2004.

BAJOS, Nathalie; FERRAND, Michèle. L'interruption volontaire de grossesse et la recomposition de la norme procréative. Sociétés contemporaines, n. 61, p. 91-117, 2006.

BERQUÓ, Elza; CAVENAGHI, Suzana. Increasing adolescent and youth fertility in Brazil: a new trend or a one-time event? In: Annals Population Association of America. Annual Meeting, session 151. Pennsylvania, Philadelphia 2005.

BERQUÓ, Elza; LIMA, Liliam Pereira. Fecundidade e aspectos reprodutivos. In: PNDS-2006, Pesquisa Nacional de Demografia e Saúde da Criança e da Mulher, Relatório final. Brasília: Ministério da Saúde, 2008. p. 113-126<http://bvsms.saude. gov.br/bvs/pnds/index.php>.

BOLTANSKI, Luc. La condition fotale: une sociologie de l'engendrement et de l'avortement. Paris: Gallimard, 2004.

BRANDÃO, Elaine Reis. Iniciação sexual e afetiva: exercício da autonomia juvenil. In: Maria Luiza Heilborn (Org.). Família e sexualidade. Rio de Janeiro: Editora FGV, 2004. p. 63-86.

BRANDÃO, Elaine Reis. Gravidez na adolescência: um balanço bibliográfico. In: Maria Luiza Heilborn (Org.). O aprendizado da sexualidade: reprodução e trajetórias sociais de jovens brasileiros. Rio de janeiro: Garamond, 2006. p. 61-95.

BRASIL, Ministério da Saúde. Pesquisa nacional de demografia e saúde da criança e da mulher - PNDS 2006: Dimensões do processo reprodutivo e da saúde da criança. Brasília $<$ http://bvsms.saude.gov.br/bvs/publicacoes/pnds_crianca_mulher.pdf $>$ ( 2 dez. 2014).

BRASIL, Ministério da Saúde. Secretaria de Atenção a Saúde. Departamento de Ações Programáticas Estratégicas. Gestação de alto risco: manual técnico. 5. ed. Brasília: Editora do Ministério da Saúde, 2010.

BRASIL, Ministério da Saúde/SVS. Sistema de informações sobre nascidos vivos (Sinasc), 2000 e 2010. Brasília, 2010. 
BUTLER, Judith. Le pouvoir des mots: discours de haine et politique du performatif. Paris: Éd. Amsterdam, 2004.

CAETANO, Rosângela; DAIN, Sulamis. O Programa de Saúde da Família e a reestruturação da Atenção Básica à Saúde nos grandes centros urbanos: velhos problemas, novos desafios. The Advance-Progress (Vidalia), v. 12, n. 1, p. 11-29, 2001.

CALVEZ, Marcel. Le risque comme ressource culturelle dans la prévention du sida. In: Jean-Pierre Dozon; Didier Fassin. Critique de la santé publique: une approche anthropologique. Paris: Ballan, 2001. p. 127-143.

CAMARGO, Keneth R. Medicalização, farmacologização e imperialismo sanitário. Cadernos de saúde pública, v. 29, n. 5, p. 844-846, 2013.

CHARBONNEAU, Johanne. La maternité chez les adolescentes : certaines s'en sortent bien. Recherche sociale, n. 5, v. 1, p. 3-5, 1998.

CHAZAN, Lilian Krakovski. Meio quilo de gente: um estudo antropológico sobre ultrassom obstétrico. Rio de Janeiro: Editora Fiocruz, 2007.

CLARKE, Adèle; FISHMAN, Jennifer R.; FOSKET, Jennifer R.; MAMO, Laura; Janet Shin. Technosciences et nouvelle biomédicalisation: racines occidentales, rhizomes mondiaux. Sciences sociales et santé, v. 18, n. 2, p. 11-42, 2000.

CONRAD, Peter. The medicalization of society: on the transformation of human condition into treatable disorders. Baltimore: The Johns Hopkins University Press, 2007.

CORRÊA, Humberto. A fecundidade na adolescência: a interpretação de um problema ou um problema de interpretação? Dissertação (Mestrado em Demografia e Estudos Populacionais), Escola Nacional de Ciências Estadísticas, IBGE, Rio de Janeiro, 2004.

CORREA, Marilena; GUILAM, Maria Cristina. O discurso do risco e o aconselhamento genético pré-natal. Cadernos de Saúde Pública, v. 22, n. 10, p. 2141-2149, 2006.

COSTA, Tonia; STOTZ, Eduardo Navarro; GRYNSZPAN, Danielle; SOUZA, Maria do Carmo Borges de. Naturalização e medicalização do corpo feminino: o controle social por meio da reprodução. Interface: Comunicação, Saúde, Educação, v. 10, n. 20, p. 363-380, $2006<$ dx.doi.org/10.1590/S1414-32832006000200007>.

DADOORIAN, Diana. Adolescentes: por que elas querem engravidar? Revista Femina, v. 24, n. 1, p. 47-51, 1996.

DE CERTEAU, Michel. L'invention du quotidien. v. 1, Paris: Gallimard, 2002.

DENYER, Laurie Michelle. Call me'at-risk': maternal health in São Paulo's public health clinics and the desire for cesarean technology. Massachusetts, 2009. Doctoral dissertation, Massachusetts Institute of Technology.

GROSSI, Miriam. Gênero e parentesco: familias gays e lésbicas no Brasil. Cadernos Pagu, n. 21, 2003, p. 261-280.

FAYA ROBLES, Alfonsina. L'humanisation de l'accouchement et de la naissance au Brésil: de nouveaux dispositifs de régulation des corps des femmes pauvres? Revue Lien social et Politiques, v. 59, p. 115-124, 2008. 
FAYA ROBLES, Alfonsina. Las agentes comunitarias de salud en el Brasil contemporáneo: la "policía amiga" de las madres pobres. Revista Latinoamericana Sexualidad, Salud y Sociedad, n. 12, p. 92-126, 2012.

FAYA ROBLES, Alfonsina. Régulations en santé materno-infantile en milieu populaire à partir de la notion de risque. Anthropologie \& Santé, n. 9, $2014<\mathrm{http}: / /$ anthropologiesante.revues.org/1525> (6 jan. 2015).

FOUCAULT, Michel. Le Souci de soi, tomo 3: "Histoire de la sexualité". Paris: Gallimard, 1984.

HEILBORN, Maria Luiza. Gravidez na Adolescência: considerações preliminares sobre as dimensões culturais de um problema social. In: Elisabeth M. Vieira; Maria Eugenia L. Fernandes; Patrícia Bailey; Arlene McKay (Orgs.). Seminário Gravidez na Adolescência, Saúde do Adolescente. Rio de Janeiro, Ministério da Saúde, Projeto de Estudos da Mulher/Family Health International, Associação Saúde da Família, 1998. p. 23-32.

HEILBORN, Maria Luiza; SALEM, Tânia; ROHDEN, Fabíola; BRANDÃO, Elaine; KNAUTH, Daniela; VÍCTORIA, Ceres; AQUINO, Estela; McCALLUM, Cecília; BOZON, Michel. Aproximações socioantropológicas sobre a gravidez na adolescência. Horizontes Antropológicos, v. 8, n. 17, p. 13-44, 2002.

HEILBORN, Maria Luíza. Experiência da sexualidade, reprodução e trajetórias juvenis. In: Maria Luiza Heilborn; Estela M. L. Aquino; Michel Bozon; Daniela Riva Knauth (Orgs.). $O$ aprendizado da sexualidade: reprodução e trajetórias sociais de jovens brasileiros. Rio de Janeiro: Ed. Garamond, 2006. p. 30-58.

HISLOP, Jenny; ARBER, Sara. Understanding women's sleep management: beyond medicalization-healthicization? Sociology of Health \& Illness, n. 7, v. 25, p. 815-837, 2003.

IBGE-Instituto Brasileiro de Geografia e Estatística. Censo demográfico 2010. <www. ibge.gov.br> (2 nov. 2014).

JACQUES, Beatrice. Sociologie de l'accouchement. Paris: PUF, 2007.

KATZ, Regina Abramovitch. Adolescentes e maternidade: um destino, um problema, uma escolha? Dissertação de mestrado em Saúde da Criança, Instituto Fernandes Figueira, Fundação Oswaldo Cruz. Rio de Janeiro. 1999.

LEAL, Ondina Fachel; LEWGOY, Bernardo. Pessoa, aborto e contracepção. In: Ondina Fachel Leal (Org.). Corpo e significado: ensaios de antropologia social. Porto Alegre: Editora da Universidade, 1995. p. 55-75.

LEAL, Ondina; LEWGOY, Bernardo. Aborto: uma contribuição antropológica à discussão. Revista Filosofia Politica: Nova Série. v. 2, p. 173-195, 1998.

MARTINS, Terezinha Costa, HEILBORN, Maria Luiza. Gravidez na adolescência e fatores de risco entre filhos de mulheres nas faixas etárias de 10 a 14 e 15 a 19 anos em Juiz de Fora, MG. Revista APS, v. 9, n. 1, p. 29-38, 2006.

MEMMI, Dominique. Faire vivre et laisser mourir: le gouvernement contemporain de la naissance et de la mort. Paris: La découverte, 2003.

MEMMI, Dominique. Administrer une matière sensible: conduites raisonnables et pédagogie par corps autour de la naissance et de la mort. In: Didier Fassin; Dominique Memmi (Orgs.). Le gouvernement des corps. Paris: Éd. de l'EHESS, p. 135-154. 2004. 
ROSE, Nikolas. Inventando nossos selfs. Psicologia, poder e subjetividade. Petrópolis: Editora Vozes, 2011.

SECRETARIA Municipal de Saúde. Bairros Cariocas, Rio de Janeiro, $2010<\mathrm{http}: / /$ portalgeo.rio.rj.gov.br/bairroscariocas> (5 nov. 2014).

SCOTT, Russel Parry. Risco, reprodução e gênero na mortalidade infantil. $31^{\circ}$ Encontro Anual da Anpocs, Caxambu, 22 a 26 de outubro 2007.

SIMÕES, Celso. A transição da fecundidade no Brasil: análise de seus determinantes e as novas questões demográficas. São Paulo: Arbeir Factory, 2006.

TESSER, Charles Dalcanale. Medicalização social (I): o excessivo sucesso do epistemicídio moderno na saúde. Interface: Comunicação, Saúde, Educação, v. 10, n. 19, p. 61-76, 2006.

TORNQUIST, Carmen Susana. Armadilhas da nova era: natureza e maternidade no ideário da humanização do parto. Estudos Feministas, n. 2, v. 10, p. 483-492, 2002.

UZIEL, Anna Paula. Parentalidade e conjugalidade: aparições no movimento homossexual. Horizontes Antropológicos, n. 26, v. 12, 2006, p. 203-227.

VÍCTORA, Cesar; AQUINO, Estela; LEAL, Maria do Carmo; MONTEIRO, Carlos Augusto; BARROS, Fernando; SZWARCWALD, Celia. Saúde de mães e crianças no Brasil: progressos e desafios. The Lancet, series, 11, p. 32-46, $2011<$ http://download. thelancet.com/flatcontentassets/pdfs/brazil/brazilpor2.pdf $>$.

Recebido em: 7 jul. 2014

Aprovado em: 12 jan. 2015

Autora correspondente: Alfonsina Faya Robles 74, rue du Général Bourbaki 31200 - Toulouse, França 